\title{
CRÍSIPO DE SOLÓS Y LOS INDEMOSTRABLES
}

\author{
Alejandro Ramírez Figueroa \\ Universidad de Chile \\ alramire@uchile.cl
}

\begin{abstract}
Resumen / ABSTRACT
De acuerdo con los principales enfoques al respecto (Sexto, Diógenes Laercio, Galeno, B.Mates, Long, Bochenski, Lukasiewicz) la lógica (dialéctica) de los estoicos es principalmente un sistema deductivo, lo que, en términos actuales, ha sido visto como un sistema de lógica proposicional. La obra de Crísipo acerca de los cinco argumentos indemostrables constituye la principal base de dicho sistema. En este artículo se examina la naturaleza de dichos cinco indemostrables así como el llamando teorema de Antipatro y los esquemas básicos de inferencia, o zemas. Por otra parte y en particular, sostengo que dichos argumentos indemostrables tienen otro importante rol para la filosofía y la historia de la lógica, cual es el de constituirse en una justificación de la deducción, un problema central en el presente. Se analiza, primero, la justificación por los indemostrables y por el principio de condicionalización y, segundo, la justificación cognitiva de la lógica implícita en un sistema estoico.
\end{abstract}

Palabras clave: Crísipo de Solós, lógica, indemostrable, justificación, validez.

\section{CHRYSIPPUS OF SOLI AND THE INDEMONSTRABLES}

Acording to standard approaches (Sextus, Diogenes, Galeno, B.Mates, Long y Sedley, Bochenski, Lukasiewicz), the Stoic logic is actually a deduction system, a propositional system of logic in today perspective. The work of Chrysippus about the five indemonstrable arguments is the principal basis of this system. In this paper I examine the nature of indemonstrable arguments, the Antipater's theorem and the basic schemas of inference, or zemas. On the other hand, in particular I hold that the indemonstrable arguments have another important role for philosophy and history of logic; this role is the justification of deduction, a central problem at present. I analize, first, the indemonstrable and conditional justification of deduction and second, the cognitive justification of logic implied in stoic system.

KEYWORDS: Chrysippus of Solos, logic, non-demonstrable, justification, validity. 


\section{Introducción}

RA

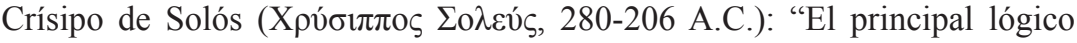
de la Stoa", según Long y Sedley (Long y Sedley 1987, Vol. I, p. 188)', es señalado por la tradición como el creador de la tesis de la existencia de al menos cinco esquemas argumentativos indemostrables en la dialéctica (hoy lógica), cuya propiedad central es la de ser irreductibles a ningún otro esquema, ni tampoco entre sí, pero a los cuales todos los demás argumentos se pueden reducir. La interpretación consensuada que se hace de dichos cinco esquemas es que se trata del establecimiento de las bases de un sistema de lógica. Así lo entienden, por ejemplo, B. Mates² (1985), Bochenski (1961) y Kneale y Kneale (2008). Kneale y Kneale, por ejemplo, afirman que Crísipo logró derivar formas complejas de argumentos a partir de cinco formas indemostrables (2008, p. 175). Mates, por su parte, expone que los estoicos concebían la dialéctica proposicional como completa, esto es, como un sistema en que cualquier argumento será considerado como válido si se lo puede probar teniendo como base algunos de los cinco esquemas no demostrables (Mates, p. 139) o, de otra manera, será considerado válido si se lo puede reducir a alguno de los indemostrables. Lo mismo expone Bochenski en su texto de 1961, al referirse a la dicotomía demostrableno demostrable en los estoicos. Queda así, a la vista, de manera preliminar, que los indemostrables están comprometidos con la validez lógica de un argumento y con la idea actual de sistema lógico.

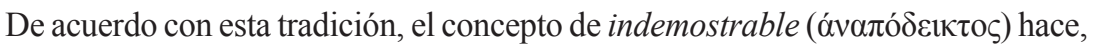
pues, referencia a una propiedad de un sistema lógico, esto es, a la naturaleza de la lógica en cuanto conjunto interrelacionado de enunciados mediante conexiones demostrativas a partir de ciertos principios y reglas indemostrados ${ }^{3}$. Sin embargo, no obstante haber

1 Galeno consideraba que había dos grandes tipos de "silogismos" (que hoy traducimos por sistemas deductivos): el de Artistóteles y el de Crísipo, y que muchos aristotélicos de la época tenían por superior al de Crísipo (referido en Bochenski 1947, p. 15). Por su parte, Lukasiewicz ( 1934 / en 1986, p. 119), en su análisis comparativo entre la lógica peripatética y la de los estoicos, afirma: "Los estoicos han de contar con nuestro agradecimiento por haber echado los cimientos de esta admirable teoría". El pensamiento contemporáneo comenzó a preocuparse de la lógica estoica ya antes de Lukasiewicz con el texto de E. Bréhier (1919/2005); actualmente puede consultarse J. Gould (1970, 1974), J. Corcoran (1974), y más recientemente los trabajos de J. Gourinat (2000), los textos sobre lógica estoica reunidos por J. Brunschwig (2006) y los trabajos reunidos por Gourinat y Lemaire (2016).

2 Mates (1985) defiende la idea de que este sistema no puede denominárselo axiomático propiamente tal, como sí lo entendía Lukasiewics. Como se verá más adelante, en la sección 2 , ello se debe a que los estoicos no solamente llamaban "indemostrable" a ciertos esquemas básicos irreductibles sino que, también, a los compuestos de estos.

3 Falguera y Martínez (1999, p. 58) definen: “Un sistema lógico es, pues, un cuerpo teórico que consiste en un conjunto de esquemas lógicos, algunos de los cuales se presentan como básicos y los demás como dserivados, que se toman como criterios de validez de determinado 
consenso en la tradición acerca de esta interpretación, parece posible especular si esa es la única forma de entender la tesis de Crísipo. Se examina, entonces, si el concepto de argumento indemostrable se agota en el de sistematicidad. Lo que se plantea aquí es que no solo se trata de la idea de que hay algunas estructuras inferencialmente válidas que son básicas, capaces de estructurar todas las demás, sino que, además, la tesis de Crísipo parece contener la idea de que constituyen los indemostrables un expediente de justificación de la deducción, cuestión ésta relevante en la filosofía de la lógica actual.

Cuando se pregunta cómo es que confiamos y creemos en que un determinado argumento sea válido, de ordinario contamos con esta respuesta: es que dicho argumento responde a las leyes de la lógica, deductiva, precisamente ${ }^{4}$. La pregunta por la justificación está un paso más atrás de eso, es la pregunta por las razones que tenemos ahora para creer en la validez de las leyes y reglas de la lógica. Susan Haack posiciona, al inicio de su artículo de 1996, la justificación de la deducción como una cuestión relevante en la filosofía de la lógica:

A menudo es tomado por garantizado por los escritores quienes proponen $-\mathrm{y}$, sobre esto, por quienes se oponen- la "justificación" de la inducción, que la deducción o bien no la necesita o bien fácilmente puede ser provista de una justificación". Y agrega inmediatamente: ... "Al contrario de la opinión común problemas análogos a los que, notoriamente, aparecen en los ensayos de justificación de la inducción, también aparecen en los ensayos por justificar la deducción" (Haack 1996, p. 183) ${ }^{5}$.

El problema de la justificación de la deducción (mucho menos estudiada que la justificación de la inducción, como afirma Haack), en sus formulaciones actuales en filosofía de la lógica, puede plantearse de muchos modos, por ejemplo ${ }^{6}$ :

tipo de argumentos". En términos algo distintos hoy la idea de sistema lógico $\mathrm{S}$ se define como una estructura, con un lenguaje formal y una base deductiva; $\mathrm{S}=\langle\mathrm{L}, \mathrm{D}\rangle$.

$4 \quad$ No se aborda aquí la justificación de la corrección de sistemas no deductivos.

5 Haack también analiza la postura de M. Dummett sobre la justificación de la deducción. Ver Haack 1996a.

6 La pregunta por la justificación de la deducción (o de la lógica sin más, si se la entendiese, hoy algo estrechamente, como una teoría de la deducción) tiene expresiones actuales como las siguientes: “¿Cómo sabemos que una verdad lógica lo es? ¿Cómo sabemos que una regla de inferencia es válida?” (Martínez 2007, p. 83); de igual modo, aludiendo al Modus Ponens: “¿En virtud de qué estamos justificados en emplear esta regla de inferencia?” (Schechter y Enoch 2006, p. 687); o, “Cómo yo justificaría mi creencia de que la lógica clásica, por ejemplo, es correcta?" (Fisher 2008, p. 178); o, “¿Cómo es posible para nosotros estar justificados sobre nuestras leyes lógicas fundamentales?” (Boghossian 2000, p. 229); o, también: "A las reglas de inferencia se las considera el alfa y el omega de la lógica (...) ¿En qué se basan las reglas de inferencia? ¿De dónde vienen?” (Hintikka y Sandu 2007, p. 15). Siguiendo a Hume, algunos autores (D. Bradley 2015) consideran la justificación solamente como una cuestión epistemológica atingente a las inferencias no válidas, justamente porque las válidas no necesitarían justificación dado que implican la consecuencia. Sin embargo, 
- Si el argumento A está justificado en cuanto lo aceptamos como válido merced a que tiene la forma válida $A^{`}$, ¿qué permite considerar válida a su vez $A^{`}$ ?

De una manera análoga:

- $\mathrm{Si}$, desde un punto de vista sintáctico, en $\mathscr{D}=\left(a_{1} a_{2, \ldots}, a_{n-1,} a_{n}\right)$ se considera que $a_{n}$ ha sido derivadade $\left(a_{1} \ldots a_{n-1}\right)$ según $\mathscr{K}_{\text {s }}$ ¿qué permite considerar válida a $\mathscr{K}$, que no sea circularmente, esto es, considerando que $\mathscr{K}$ es válida porque permite derivar $a_{n}$ ?

- Pero ya encontramos en las fuentes antiguas, en Epícteto (50-138 DC), una expresión del problema de la justificación de la deducción: La razón ( $\lambda$ ó $о \varsigma)$ es la que articula o estructura ( $\delta 1 \alpha \rho \theta \rho \omega ́ v)$ todo lo demás; pero, a ella misma,

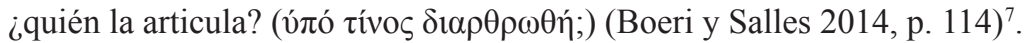

Pero no se trata tanto de preguntar qué justifica la conclusión, pues una respuesta sería que lo hacen las premisas, lo cual también presenta muchos problemas ${ }^{8}$. La pregunta es por la justificación de la validez del argumento completo, por el "paso" de las premisas a la conclusión. Las respuestas son variadas, pero se pueden centrar en la siguiente taxonomía, entre otras posibles: (a) La deducción no requiere justificación debido a su propia naturaleza; (b) La deducción sí requiere justificación, lo que abre a su vez la siguiente distinción básica: (b)1. Requiere justificación y se justifica mediante la misma lógica, por ejemplo, acudir a la tesis de las tablas de verdad, al teorema de corrección, el concepto de armonía de Dummett (1993), lo que se ha denominado hoy en día, el problema del logocentrismo (R. Hanna 2006); (b)2. Requiere justificación y ello ocurre apelando a la semántica y al convencionalismo; la validez se justifica en la analiticidad ${ }^{9}$;

en la filosofía actual de la lógica, la pregunta por la justificación también aparece como un problema para la deducción.

7 El problema de la justificación, pero en la epistemología no en la filosofía de la lógica, se encuentra claramente planteado en el trilema del escéptico Agripa, de una manera que pervive hasta hoy en la teoría del conocimiento (Ver Sexto (1933) 2000, I, 164). En términos más generales, el problema de la justificación de X puede enunciarse como la necesidad de contar con buenas razones positivas para aceptar X. Tradicionalmente no se ha considerado que la deducción tenga que tener justificación alguna, puesto que se justifica a sí misma. Pero ello implica aceptar que lo que justifica algo es solamente la razón lógico-deductiva, cuestión que hoy la filosofía de la lógica ha puesto en cuestión.

$8 \quad$ Ver al respecto Haack 1996, p. 190.

9 Ver sobre la justificación el desarrollo que realiza M. García-Carpintero (1993), quien concentra la cuestión en al menos tres enfoques: la concepción cuantificacional de la justifuicación, de Frege-Russell; el enfoque según el cual la verdad lógica y la consecuencia lógica lo son por analiticidad y, finalmente, su defensa (contra la postura de J. Etchemendy) de que tales dos propiedades lógicas se basan más bien en la concepción modelo-teorética de la lógica, cuyo origen es la idea de interpretación de Tarski. 
(b)3. Requiere justificación y ello ocurre mediante expedientes extralógicos, como son tesis epistémicas, intuitivas, cognitivas, por ejemplo.

En la segunda sección siguiente se expone los 5 indemostrables y las reglas asociadas de reducción en cuanto cumplen un rol sistemático. En la sección tercera se examina en qué sentido los indemostrables y otros componentes del sistema lógico de Crísipo, el principio de condicional y lo cognitivo implícito, pueden ser entendidos, también, como justificatorios, y en qué categoría taxonómica de justificación, como la recién descrita, se pueden insertar.

\section{El sistema de Crísipo y el análisis reductivo}

Bonevac y Dever (2012, p. 185) aducen que la idea de validez lógica estoica es imprecisa. Ello puede deberse a que hay más de un criterio manejado por dicha escuela, como son la existencia de los indemostrables, el principio de condicionalización, el análisis reductivo a ciertas estructuras indemostrables. En lo que sigue nos centraremos preferentemente en este último enfoque.

Como lo expone Mates (1985, p. 139), Sexto (160-210 D.C. $)^{10}$ (2000, L. II. 157) plantea, en su análisis del pirronismo, que los estoicos imaginaban muchos argumentos que eran indemostrables, pero que había al menos cinco a los cuales se puede reducir todo argumento. Pero no solamente los indemostrables formaban parte fundamental del sistema sino que había ciertas reglas, $\theta \varepsilon ́ \mu \alpha \tau \alpha$ (o también llamados $\Theta \varepsilon \omega \rho \eta ́ \mu \alpha \tau \alpha$, según Bochenski 1961, p. 127) que permitían llevar a cabo las demostraciones a partir de los indemostrables. Dice Diógenes Laercio:

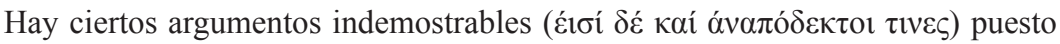
que no requieren demostración. Ellos son empleados en la construcción de cada argumento. El número de ellos varía según los autores, pero Crísipo ofrece cinco de ellos (Diógenes Laercio 180-240 D.C. / 2005, L. VII. 79).

El primer indemostrable tiene la siguiente forma, siempre en la exposición de Diógenes Laercio (L. 7, de 79 a 81) y en la forma de expresión utilizada entonces: (i) Si lo primero entonces lo segundo; (ii) Lo primero; (iii) Lo segundo. Diógenes ofrece el siguiente ejemplo: "Quién divulgue los misterios a los iniciados es culpable de impiedad. El hierafante ciertamente revela los misterios a los no iniciados. Por tanto es culpable de impiedad" (Diógenes Laercio 2005, L. VII, 186).

10 Las principales fuentes para los indemostrables y para la obra de Crísipo son Sexto, Diógenes Laercio, Dionisio Thrax, Alejandro de Afrodisia, Cicerón, Galeno, Luciano, Gellio. Véase la referencia de B. Mates (1985) acerca de las diferentes expresiones en cada fuente. Por su parte, Diógenes Laercio (2005) ofrece, en L. VIII, 190 y ss., un listado de las obras de Crísipo, las que fueron muchas, pero de las cuales no se ha conservado ninguna. 
El segundo indemostrable es: (i) Si lo primero entonces lo segundo; (ii) No lo segundo; (iii) No lo primero.

Tercer indemostrable: (i) No lo primero y lo segundo; (ii) Lo primero; (iii) No lo segundo. Hay que indicar aquí que este indemostrable es interpretable como el enunciado: $\left(\left(\neg p^{\wedge} q\right)^{\wedge} p\right) \rightarrow \neg q^{11}$ y que puede tener otra forma, también lógicamente verdadera. lo segundo.

Cuarto indemostrable: (i) Lo primero o lo segundo; (ii) Lo primero; (iii) No

Quinto indemostrable: (i) Lo primero o lo segundo; (ii) No lo segundo; (iii) Lo primero.

Sexto Empírico, en Contra los lógicos, alude solamente a los tres primeros indemostrables a los que denomina formas simples, pues afirma que hay otros que son compuestos de los simples. En la formulación del tercer indemostrable hay una sutil variación respecto de la de Diógenes, aunque no tiene consecuencias respecto de su validez, y corresponde a la formalización indicada en la nota 3 a pie de página, esto es en la negación de una conjunción como primera premisa: "No: tanto es de día como

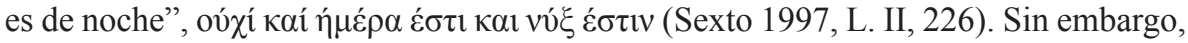
en los Esbozos Pirrónicos, Sexto expone los 5 indemostrables de modo coincidente en su forma con la exposición de Diógenes.

Galeno (S. II D.C.), al referirse a Crísipo, refiere también los 5 indemostrables. Según el autor, los argumentos indemostrables son aquellos que tienen por primera premisa una premisa trópica, ( $\tau \rho \mathrm{i}$ ís, quilla de un barco, esto es, elemento estructurador del conjunto), de la forma de una implicación, conjunción o conjunción negada. Plantea solamente una diferencia en el quinto indemostrable en su formulación respecto de la exposición de Diógenes: (i) "O lo primero o lo segundo; (ii) No lo primero; (iii) Lo segundo" (Galeno, fragmento 371 acerca de Crísipo, en Crísipo de Solos 2006, p. $42^{12}$ ). Se observa que (ii) y (iii) están invertidos en las dos versiones.

Queda, pues, a la vista, que la lógica estoica, específicamente en las formulaciones de Crísipo, dio con algunas formas de lo que hoy la lógica reconoce como reglas fundamentales de la validez formal. Están allí las reglas de la deducción natural, de eliminación del condicional (indemostrables 1 y 2), la eliminación de la conjunción (indemostrable 3) y las reglas de la eliminación de la disyunción (indemostrables 4 y 5). Así, las formas de los indemostrables 4 y 5 admiten más de una forma, esto es, dada la disyunción, la segunda premisa puede ser la negación del primer disyunto o

11 También es formalizable como la tautología: $(\neg(\mathrm{p} \wedge \mathrm{q}) \wedge \mathrm{p}) \rightarrow \neg \mathrm{q}$. Esta es, en todo caso, la formulación actual en la lógica proposicional, no estrictamente la estoica. Ver B. Mates 1985, p. 124.

12 Se advierte que hay un error en la edición de Gredos (2006, p. 41), hablando de Galeno, en la formulación del primer indemostrable: Dice: "Si lo primero, lo segundo. Lo segundo, luego lo primero", lo que manifiestamente es un error. Dado que Gredos no aclara ni hace notar el error al pie de página, puede suponerse que se trata de un error de la editorial. 
del segundo disyunto; o la afirmación del primer disyunto o la afirmación del segundo disyunto, sin que estas variaciones signifiquen perder validez formal. De allí que la diferencia anotada más arriba entre las formulaciones de Diógenes y Galeno en este punto no tengan mayor significado respecto de la deducción ${ }^{13}$. Al igual que Crísipo diferenció el cuarto y el quinto indemostrable, así también hoy, la deducción natural diferencia en dos las reglas para la eliminación de la disyunción ${ }^{14}$.

El sistema lógico de Crísipo trabaja no solamente sobre los cinco argumentos básicos indemostrables. Requiere, además, de otro expediente fundamental, que son reglas cuya naturaleza no es del todo clara, pues, por una parte parecen constituirse como metarreglas para realizar las inferencias pero también parecen cumplir con una función similar a los 5 indemostrables y que se analizará más adelante. Entonces, cualquier argumento, si es que es válido, debe poder reducirse mediante un análisis a alguna de las cinco formas indemostrables.

Hay varios ejemplos en las fuentes, especialmente en Sexto, acerca de cómo se lleva a cabo este análisis reductivo a los 5 indemostrables.

Un primer ejemplo tratado por Sexto es el siguiente ${ }^{15}$ : se requiere decidir si el siguiente argumento es válido. Lo expresamos mediante su esquema ${ }^{16}$ : (i) Si 1 entonces si 1 entonces 2; (ii) pero 1, (iii) entonces 2 . Si se logra reducirlo a algún o algunos indemostrables, el argumento es válido.

Argumento original (i),(ii),(iii)
$\begin{array}{lll}\text { (i) } 1 \rightarrow(1 \rightarrow 2) & \text { Prem. } \\ \text { (ii) } 1 & \text { Prem. } \\ \text { (iii) } 2 & \text { Concl. }\end{array}$

13 Bonevac y Dever (2012, p. 184) hacen ver que los 5 indemostrables, así como otras reglas estoicas solo pueden hasta cierto punto corresponder con las actuales formalizaciones de la lógica proposicional dado que los significados de las constantes lógicas estoicas puede no coincidir del todo con las actuales. Ello ocurre con el condicional, que tenía para los estoico tres significados: el diodórico, el filónico y el de Crísipo). También la disyunción presenta diferencias de significado: la estoica no era binaria, pues según Galeno una disyunción debía tener a lo más un disyunto verdadero, de lo contrario era una pseudo disyunción.

14 Sobre las reglas de la deducción natural véase, por ejemplo, Manzano y Huertas 2004, p. 143 y ss., o también, Lemmon 2002, cap. 1.

15 Ver Sexto 1997, Contra los lógicos, VIII, 230-233.

16 Aunque los estoicos acostumbraban a tratar estos problemas no con sus esquemas, como se lo haría hoy, sino con los argumentos reales.

17 Según Sexto (1997, L.VIII 223), los estoicos llamaban indemostrables no solamente a los 5 básicos, sino que también a los compuestos de esos 5 . Sin embargo, más allá de los nombres, conceptualmente es consenso considerar como indemostrable a los 5 básicos, dado que los demás argumentos válidos efectivamennte son reductibles a los 5 , y estos 5 no son reductibles a ningún otro. 


\section{Demostración}

(iv) $1 \rightarrow 2 \quad 1$ er Indem. en (i), (ii)

(v) 2 ler Indem. en (ii), (iv)

Lo anterior significa que el argumento inicial, que es complejo, puesto que en su primera premisa hay dos condicionales, es válido, dado que se lo ha demostrado apelando a la aplicación dos veces consecutivas del primer indemostrable. Pero lo mismo puede decirse de otro modo, de un modo que revele el aspecto analítico del argumento. El argumento original, pues, es un complejo de dos argumentos, cada uno con la forma del primer indemostrable, lo que se puede graficar del siguiente modo:

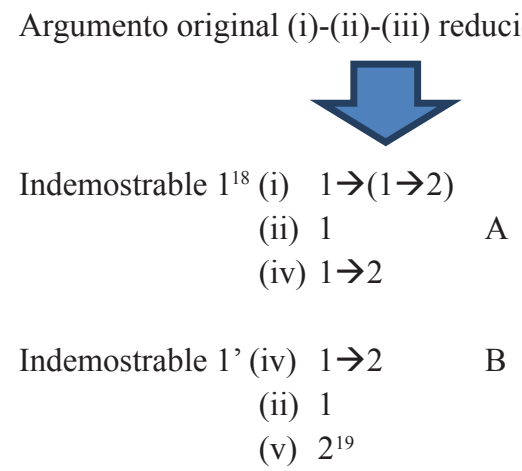

En relación con esta reducción, Sexto, en Contra los lógicos II, 223, hace una taxonomía donde queda expuesto el sentido del análisis: hay argumentos indemostrables compuestos que son reductibles a los simples y éstos no son reductibles a nada. La reducción es necesaria para que pueda aceptarse que un argumento compuesto (no-simple), sea considerado como indemostrable (ver Mates 169). Pueden hacerse al respecto algunas observaciones atingentes a las facetas de los indemostrables, a los conceptos de deducción implicados, a la idea de una estructura interna que se revelaría en la reducción y, ligado a lo anterior, al concepto de validez lógica ${ }^{20}$.

En primer lugar, los indemostrables parecen tener dos facetas distintas, pero que confluyen a lo mismo. Si bien, en el ejemplo, el indemostrable 1 concurre en ciertos puntos de la prueba y son aplicados en cierta línea para producir otra nueva a modo

18 Otros dos ejemplos de análisis y reducción a alguno de los indemostrables son expuestos por Sexto en Contra los lógicos L.VIII, 230-233 y L.VIII 234-241.

19 Véase el análisis aclaratorio que lleva a cabo sobre esto Luis Vega (1986, p. 159 y ss., específicamente la nota 11).

20 Hay buna correspondencia en esto con la idea aristotélica de conocimiento de algo por sus causas (Segundos analíticos, I, 2 71b 8-10; II, 8,93ª 4-5), en que las causas de algo deben ser finitas, por lo que debe llegarse a causas primeras incausadas que serían la base de las ciencias. 
de conclusión, y esa operación pude repertirse varias veces, también el indemostrable corresponde al resultado, por decirlo así, de esa demostración, como un resultado de la reducción. Así, el indemostrable es a la vez regla de inferencia y resultado de esa aplicación. Ambas facetas son equivalentes y no se contradicen; son dos modos en los que pueden ser considerados y entendidos los indemostrables. El indemostrable permite la deducción y a la vez es resultado del análisis.

La segunda observación tiene que ver con el concepto analítico de la deducción estoica. De acuerdo con el proceso descrito, se podría afirmar que deducir aquí es descomponer el argumento en sus elementos simples irreductibles, los indemostrables. Así, el argumento original es válido si existe para él al menos un indemostrable, aunque éste aparezca más de una vez en la demostración. En el ejemplo anterior, el argumento original se descompone en A y B, y cada uno de ellos tiene la forma de un indemostrable, $\mathrm{y}$, por tanto, hay deducción y validez.

El tercer elemento que debe destacarse es el del significado de la reducción o descomposición. Parece ser que dicho proceso tiene por resultado indicar o hacer ver lo que sucede cuando se realiza una deducción. Y lo que ocurre allí es que se muestra, o se deja en evidencia, por decirlo así, la estructura íntima del argumento original. Si se mira bien el asunto, no hay ninguna diferencia de fondo ni de resultados entre deducir la conclusión del argumento original, al estilo de lo que hoy se denomina deducción natural (a partir de la obra de Gentzen), y lograr en la reducción los indemostrables componentes finales del argumento. Lo que distingue la reducción es su sentido: al reducir, se logra revelar de qué está compuesto el argumento si es que ha de ser válido. Y sus componentes finales no son sino alguno de los indemostrables. Se puede decir, entonces, sobre la base del ejemplo, que la deducción es un proceso que se da por aplicación de una o más veces de uno o más demostrables. En el ejemplo, se aplicó dos veces el indemostrable 1. Así la estructura interna del argumento original ejemplificado es la del indemostrable 1. Ese es su sentido.

Sin embargo, en cuarto lugar, los estoicos presentaron otro concepto de validez lógica que está vigente hasta ahora y que afirma que un argumento válido lógicamente es aquel en que: "La negación de la conclusión es incompatible con el conjunto de las premisas" (Mates 1985, p. 103). Y esa idea es la que efectivamente se verifica con la reducción a indemostrables. Esta idea subyace en la lógica hasta hoy y parece ser una de las piedras de tope de todo concepto de validez. En efecto, en la reducción a indemostrables es esta idea sin duda la que justifica y respalda que haya validez; es más, parece ser la idea que respalda la validez del indemostrable mismo.

Quinto, la descomposición de un argumento original requiere al menos de las dos condiciones siguientes: a) que la conclusión del argumento original, en este caso "2" (ver ejemplo), que es lo que se quiere demostrar, debe aparecer en alguno de los indemostrables simples de la reducción. En el caso del ejemplo, "2" aparece en en el argumento B. La segunda, b) condición requiere introducir aquí un elemento nuevo que se analizará inmediatamente a continuación: debe verificarse el "teorema" de Antípatro (muerto en 130 D.C. aprox.), según el cual la conclusión de un argumento $(1 \rightarrow 2$, de A) debe aparecer en el conjunto premisas de B). 
Además de los indemostrables, Sexto Empírico enuncia que hay en el sistema

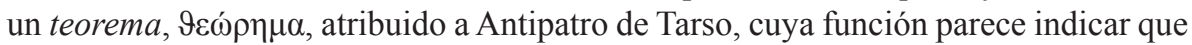
se trata en realidad de una metarregla, puesto que describe y permite llevar a cabo el análisis descrito. Afirma Sexto:

Uno debería observar que existe un teorema dialéctico que ha sido transmitido para el análisis de los silogismos, como sigue: Si conocemos las premisas que implican una conclusión, conocemos también en realidad a esta conclusión entre las premisas, incluso si no está explícitamente establecida (Sexto 1997, Contra los lógicos, L.VIII, 231).

A continuación de ese texto, Sexto explica, sobre la base del ejemplo, el mecanismo y rol del teorema. Este teorema es el que fundamenta la descomposición del argumento complejo en dos versiones del primer indemostrable. Está a la vista cómo ocurre ello: el punto central es que una vez que se ha obtenido la conclusión (iv), $1 \rightarrow 2$ en el argumento A, esta conclusión es considerada en una segunda instancia como premisa del argumento $\mathrm{B}$, para de allí derivar la conclusión, 2, obtenida en el argumento original. Sin el teorema de Antípater no habría encadenamiento, esto es el mecanismo de la deducción.

Pero hay, además, un tercer elemento a considerar en el sistema, fuera de los

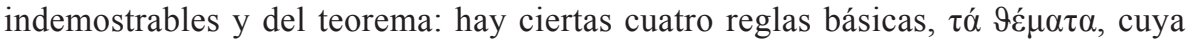
función parece ser similar a la del teorema, esto es, permitir la deducción. Según Diógenes Laercio, es Crísipo quien afirma que para la reducción a los indemostrables de un cierto argumento compuesto se debe aplicar alguna de las cuatro reglas básicas,

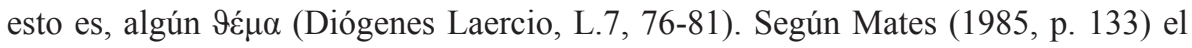
teorema no es sino una de las reglas básicas, específicamente la tercera y según Long y Sedley (2012, p. 220), el teorema parece recoger y reemplazar en el análisis a los $\vartheta \varepsilon ́ \mu \alpha \tau \alpha$ segundo, tercero y cuarto. Pero, ¿cuáles son estas reglas básicas? Las fuentes solamente respaldan la primera y la tercera. La primera está enunciada en un texto de Apuleyo (125-170 D.C.), en Sobre la interpretación, 191, 5-10 y es equiparada a la regla por imposible, aristotélica:

Hay además una regla común a todos los indemostrables. Se llama "per impossible est" y es tomada por los estoicos como la primera regla básica; la definen como sigue: si de dos proposiciones se deduce una tercera, entonces de una de ellas junto con la contradictoria de la conclusión, se deduce la contradictoria de la otra (Long y Sedley 2012, p. 218, Vol I).

Si se expresara dicha regla básica en términos de una regla estructural, se tendría:

$$
\mathrm{a}, \mathrm{b} \vdash \mathrm{c}
$$

$\mathrm{a}, \neg \mathrm{c} \vdash \neg \mathrm{b}$

No considerando las negaciones, el teorema de Antípatro parece enunciar en su máxima generalidad algo muy cercano a esta primera regla; la conclusión c está incluida en las 
premisas del segundo argumento. Las tercera regla básica se encuentra en Alejandro de Afrodisia ( S.II D.C.) acerca de los Primeros analíticos aristotélicos. Afirma allí el autor:

La así llamada tercera regla básica es así en esquema: cuando de dos proposiciones se deduce una tercera, y otras proposiciones son encontradas desde las cuales una de aquellas dos iniciales es deducida, la misma conclusión será deducida de la otra inicial más las proposiciones extras (Long y Sedley 2012, p. 218).

En términos estructurales podemos expresarlo:

$$
\mathrm{a}, \mathrm{b} \vdash \mathrm{c} \mathrm{z} \vdash \mathrm{a}
$$

$$
\mathrm{z}, \mathrm{b} \vdash \mathrm{c}
$$

En suma, tres son los elementos, pues, que constituyen, según las investigaciones actuales sobre este tema de la historia de la lógica, el sistema lógico estoico, consensuadamente sustentado e impulsado por Crísipo de Solos: indemostrables, teorema dialéctico, reglas básicas. Estos elementos muestras efectivamente lo que se quiere decir en la primera interpretación de los 5 indemostrables, esto es, que se constituyen como los pilares de la operatividad de la lógica. Y lo mismo puede decirse respecto de las reglas básicas, aunque de la aplicación de estas últimas haya muy poco registro al que echar mano para ejemplificar.

La concepción reductiva de la deducción puede expresarse mediante un principio, según el cual un argumento válido es siempre descomponible en otros argumentos válidos básicos que, en la lógica actual, corresponde a las reglas válidas de la deducción. Esta aplicación puede ilustrarse también en el contexto de la actual deducción natural, incluso en ejemplos donde debe utilizarse la regla de introducción de hipótesis y reglas que ya no corresponden a los 5 indemostrables. Por ejemplo:

Supongamos el argumento original y su descomposición en los argumentos MP y Adición (AD):

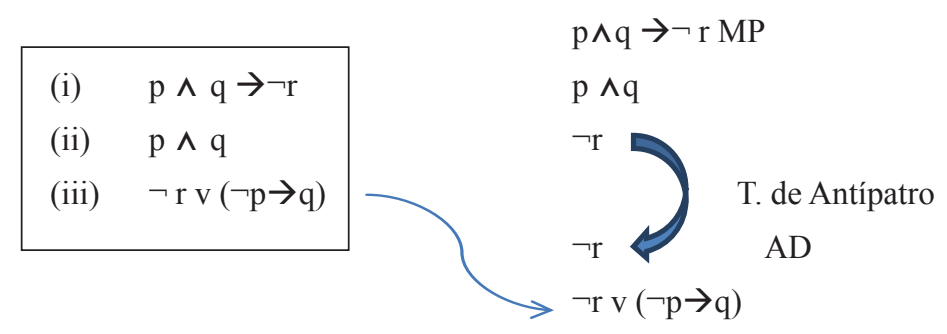

Se observan las dos restricciones fundamentales: la conclusión (iii) del argumento original es la conclusión de uno de los dos indemostrables; además, la conclusión del primer componente (MP) es premisa en el segundo (AD), lo cual es el teorema de Antipater. La estructura íntima de (i)-(ii)-(iii) es MP y AD. 
Un ejemplo donde aparece el teorema de la deducción, TD, el MP y la introducción de hipótesis $(\mathrm{IH})$ :

(i) $\mathrm{p} \rightarrow \mathrm{q} \quad \mathrm{p} \rightarrow \mathrm{q}$ IH

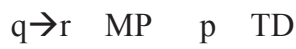

(ii) $\mathrm{q} \rightarrow \mathrm{r} \quad \mathrm{p}$

(iii)

$\underline{p}$

q
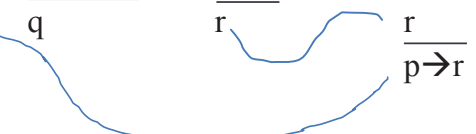

Igual que en el primer ejemplo, se observa el Teorema de Antipatro respecto de la conclusión y premisa $r$ así como la aparición en TD de la conclusión del argumento original (i)-(ii)-(iii), $\mathrm{p} \rightarrow \mathrm{r}$. La estructura íntima del argumento es IH-MP-TD

\section{Los indemostrables de Crísipo y la justificación de la deducción}

Mas, como preguntamos al inicio, ¿es el rol sistemático el único posible de considerar para los indemostrables y las reglas básicas? ¿Hay en la lógica estoica algún planteamiento acerca de la justificación de la deducción? ¿Qué justifica la aceptación de la validez lógica planteada por el sistema dialéctico estoico?

Pero, antes de dar respuestas a dichas preguntas, y tratándose aquí de la lógica antigua, cabe hacer una aclaración de atingencia; se trata de la justificación de la deducción, de la validez, no de lo que los antiguos llamaban la demostración o prueba. Aristóteles (2004), en los Segundos Analíticos, estableció las condiciones de la prueba, que son condiciones epistemológicas del conocimiento adquirido mediante argumentos, y no solamente las condiciones de validez del silogismo. Sexto, por su parte, establece cinco condiciones para que un argumento se constituya en la prueba, ү́ ́́ validez solamente una de esas condiciones. Dichos constreñimientos son epistémicos, tienen que ver con la verdad de las premisas y con la exigencia de que la conclusión no sea evidente ${ }^{21}$. Así, el problema de la justificación, que se explora aquí, tiene que ver no con la prueba, como la entendía Aristóteles, sino con la validez formal del argumento, con lo que hoy se denomina consecuencia lógica ${ }^{22}$ (en términos semánticos) o con la derivación (en términos sintácticos).

Las fuentes de la lógica estoica y de Crísipo permiten especular que la justificación de la deducción es algo complejo, pues estaría contenida en el sistema al menos en tres aspectos: primero, en los indemostrables como expedientes justificatorios; segundo, en

21 Las cinco condiciones de Sexto son: 1) la prueba debe ser un argumento; 2) Debe ser conclusiva; 3) También debe ser verdadera; 4) La conclusión debe ser no evidente; 5) La conclusión debe ser descubierta mediante el poder de las premisas (Sexto 1997, L.VIII 310, p. 403).

22 Lo que los lógicos medievales, como William Burleigh, teorizaron como consecuentia. Ver W. Burleigh 2009. 
la cuestión de la base condicional (condicionalización) de los indemostrables ${ }^{23}$; tercero, el principio de la incompatibilidad de la verdad de las premisas con la falsedad de la conclusión, y cuarto, en un acto que es extralógico, un acto cognitivo de aprehensión directa de la validez de los indemostrables. Los tres primeros se inscriben en lo que autores contemporáneos definen como logocentrismo. El cuarto, en cambio, está más allá de eso, según la taxonomía ensayada al final de la sección 1.

3.1. Los indemostrables como factor justificatorio de la creencia deductiva. Los lógicos y filósofos estoicos no plantearon la cuestión de la justificación de manera directa sino que hay que rastrearla en los textos en que exponen su sistema. Los argumentos indemostrables, de acuerdo con lo expuesto, no parecen constituirse, ellos mismos, como justificación de la deducción. Ello queda de manifiesto en el rol que juegan en la demostración, en la que se constituyen en las formas inferenciales mediante las cuales se produce la deducción sin que ellas mismas puedan reducirse a ninguna otra forma más básica. Pero, además, el sistema también está constituido por los 4 zémas, que, como se vio, también son reglas inferenciales básicas, con lo que cabe afirmar que son los 5 indemostrables y los 4 zémas los que hay que considerar en su conjunto, pues no habría razones para elegir alguno de esos dos grupos por sobre el otro. Por otra parte, tenemos el teorema de Antípater, que aglutina a los zémas, con lo que ya hay tres conjuntos de inferencias básicas.

Cabe advertir una cierta ambigüedad en el rol de los tres elementos mencionados, pues, por un lado parecen ser los indemostrables aquellos elementos inferenciales a los cuales se reducen los argumentos reales, reducción hecha por los zémas y, por otra parte, parecen ser los mismos indemostrables los que permiten la deducción. Dada la escasez de claridad que puede obtenerse de las fuentes, dicha ambigüedad permanece. Ello puede constatarse en el ejemplo de deducción analizado en la sección anterior.

Según lo anterior, si los indemostrables y los zémas fuesen la justificación de la deducción, ¿qué justifica a la regla básica indemostrable y a los zémas? Al fin y al cabo ambos tipos son inferencias, son reglas de la deducción que inmediatamente levantan dicha pregunta, son reglas que son parte del funcionamiento del sistema, no algo exterior al mismo. Los indemostrables y los zémas son, pues, parte del aparato deductivo propiamente tal y, en tal sentido, no tendrían una función justificadora sin remitirse al infinito. Además, si la justificación radica en la reducción a indemostrables, entonces la justificación coincidiría simplemente con el criterio de validez, lo cual conduciría a que lo que justifica la deducción es la validez, lo cual es extraño, por redundancia.

Si se acepta el criterio justificatorio de la reducción, dicho criterio es logocéntrico, según la taxonomía inicial, lo que significa que es circular, lo que conduce a pensar

23 Que los indemostrables cumplan una función epistémica de justificación, además de ser parte del sistema deductivo mismo, lo insinúan Asmus y Restall 2012, p. 21. Estos modos indemostrables podrían ser usados para justificar posteriores argumentos. 
que los indemostrables y los zémas no parecen ser buenos candidatos a tener un rol justificatorio.

3.2. Pero, si los 5 indemostrables y los zémas no pueden justificar ¿lo sería el principio de condicionalización presentado por Sexto?

Afirma Sexto, en Contra los lógicos:

Y ellos dicen que el que un argumento conclusivo se lo juzga como conclusivo ${ }^{24}$ cuando la conclusión se sigue de la conjunción de las premisas. Por ejemplo, un argumento como el siguiente (cuando es de día): "Si es de noche, está oscuro; Es de noche; Luego está oscuro", se dice que es conclusivo, aunque es falso, ya que su conclusión nos conduce a la falsedad. Pues, conjuntando las premisas de este modo: "Es de noche y si es de noche está oscuro", construimos un condicional que tiene por antecedente a esta conjunción y por consecuente a la conclusión: "Está oscuro". Este condicional es verdadero pues nunca comienza con verdad y termina en falsedad (Sexto 1997, L.II (VIII), 415).

Es notable la distinción que hace aquí Sexto entre "verdadero" y válido". En efecto, cuando es de día, y, cuando se está profiriendo la conclusión "está oscuro", ésta es falsa. Sin embargo, Sexto plantea claramente que el argumento no obstante lo anterior es válido, pues "nunca" se dará la combinación verdad-falsedad entre premisas y conclusión. Pero ese "nunca" no es aquí filónico, sino diodórico; nunca se dan las circunstancias fácticas para que ello ocurra. Esto da que pensar; la cuestión de la formalidad de la validez lógica, ¿no descansa finalmente en la imposibilidad fáctica? Hoy esta posibilidad ha sido abandonada en la filosofía de la lógica pero sin ofrecer algo de reemplazo (ver Mates 1985, pp.128 y ss.), que no sean las reglas estructurales que definen la validez en la filosofía actual de la lógica.

Un poco más adelante afirma Sexto:

Así pues, un argumento es conclusivo fuerte cuando, luego que hemos combinado las premisas y construido el condicional que comienza con a la conjunción de las premisas y termina por consecuente con la conclusión, se halla que el condicional es verdadero (Sexto 1997, L.II (VIII), 417).

Reafirma Sexto esta idea de la siguiente manera: "Y dicen que un argumento es válido siempre que hay un condicional verdadero que tiene por antecedente a la conjunción de las premisas y por consecuente a la conclusión" (Sexto 1997, (VIII) II, 426).

En los Esquemas pirrónicos, Sexto aclara y sintetiza la analogía entre argumento y condicional: "Pues se considera válida una prueba cuando la conclusión se sigue de la tanto B. Mates lo hace como "argumento válido". 
conjunción de las premisas como un consecuente se sigue de un antecedente" (Sexto, Hip. Prrónicas, L.II, 113).

¿Puede considerarse justificatorio de la deducción al principio del condicional o es simplemente un criterio de validez? A primera vista pareciera que es lo primero, pues está un escalón más abajo que las reglas indemostrables. El condicional tautológico formado por las premisas y la conclusión es condición de validez del argumento en cuestión; así, se lo puede enunciar: $\Gamma \vdash$ a si $\Gamma \rightarrow$ a (Hay que considerar que, según el ejemplo de Sexto expresado más arriba, el condicional en cuestión $\Gamma \rightarrow$ a era considerado diodórico y el argumento es válido, entonces solo si realmente "es de día", esto es, bajo esa condición fáctica).

Según el principio de condicionalización, entonces, respecto de cualquier indemostrable, se tiene que, por ejemplo: el primer indemostrable es válido $\mathrm{si}\left((\mathrm{p} \rightarrow \mathrm{q})^{\wedge} \mathrm{p}\right)$ $\rightarrow \mathrm{q}$ es una tautología, en términos actuales, o es un condicional diodórico, según Sexto. El segundo indemostrable es válido si $\left((\mathrm{p} \rightarrow \mathrm{q})^{\wedge} \neg \mathrm{q}\right) \rightarrow \neg$ es tautológico, y así con los tres restantes indemostrables. Esto significa que podría entenderse que los indemostrables encuentran su justificación en el principio de condicionalización. Si este principio es considerado metalógico, entonces podríamos considerarlo justificatorio y encontrar en él un expediente de fundamentación para la deducción.

Sin embargo, Mates plantea que la condicionalización ni siquiera es un criterio de validez y menos justificatorio, sino más bien, y así se lo interpreta hoy, es una característica descriptiva de cierta propiedad de los argumentos válidos. Pero, el mismo Mates afirma que, coincidentemente, el principio de condicionalización aparece en Sexto siempre en relación con la búsqueda de criterios de validez (por ejemplo, Sexto 1997, VIII, 415). Por ello, el problema al respecto no presenta la suficiente claridad. Se podría arriesgar la hipótesis de que si bien hoy la condicionalización no constituye criterio de validez sí lo era para los estoicos. Los principios metalógicos de la lógica parecen estar en el límite: pertenecen a la lógica misma y están más allá. Esta es la razón por la cual S. Haack consideraría que la apelación al principio de condicionalización es circular. Y esto debido a que finalmente la validez, por ejemplo, del modus ponens, descansaría a su vez en el significado de la constante lógica condicional. Pero esta ha sido una discusión no finiquitada, pues también se ha planteado la alternativa inversa: que el significado del condicional proviene de su rol en la inferencia ${ }^{25}$. Justamente el principio de condicionalización apela a una relación entre verdad lógica-validez que encontraría su base en que el condicional verdadero lo es en virtud de las tablas de verdad, lo cual es circular.

25 Este debate se dio entre A. Prior y N. Belnap. Prior critica la tesis de que el significado de una constante lógica pueda reducirse a reglas de inferencia, al uso que allí tenga la constante. Belnap critica a Prior y defiende que son las reglas las únicas que pueden cargar de significado a una constante. Véase Prior (2000) y Belnap (2000) en Bonnay y Cozic (2000). 
Postular que la deducción se justifica por los indemostrables es inadecuado por circular y logocéntrico. Pero, un paso más atrás, justificar los indemostrables por el principio de condicionalización parece de una circularidad más débil y no logra mejorar las cosas.

3.3. El acto cognitivo de autoevidencia y los indemostrables. Los filósofos y lógicos estoicosse acercaron a otro planteo acerca de la justificación de la deducción al afirmar de diversos modos la cuestión de la autoevidencia. En Epícteto, Sexto, Diógenes Laercio, Galeno se hallan tales expresiones que apuntan a lo mismo.

Epícteto, el esclavo liberto (50-138 D.C.), es, quizás, el único autor con un registro explícito de la pregunta por la justificación de la lógica entre los estoicos: La lógica es algo necesario. Es la razón el criterio que articula todo lo demás, pero surge la pregunta: ¿qué la articula a ella? La necesidad de la pregunta se funda en que, según el autor, antes de hacer una medida, por ejemplo, debemos entender qué es la medida. Lo mismo con la lógica. Epícteto establece esta taxonomía básica: será la misma razón o algo distinto y superior a ella lo que la justifica. La segunda alternativa nos remite al infinito (anatema para el pensamiento griego). En consecuencia, la lógica debe articularse a sí misma (Boeri y Salles 2014, p. 99). La validez deductiva, al menos en sus reglas más básicas, debe autojustificarse, lo que hoy se traduce en algunas ocasiones en la idea de lo a priori. La respuesta de Epícteto da a entender otra cosa algo más precisa: que la lógica no requiere articulación (justificación) pues es ella misma, en su naturaleza, justificada. Pero esto no es sino equivalente a postular que la razón tiene una cierta fuerza cognitiva capaz de ver la validez en su inmediatez.

Aunque fuera de Epícteto no se encuentran formulaciones explícitas del asunto, esta idea de autojustificación es la que parecen sustentar los filósofos antiguos. Esa sería, pues, la justificación de los indemostrables, más allá del principio de condicionalización.

Sexto Empírico establece el siguiente análisis del término "indemostrable":

...El término indemostrado, empecemos por él, tiene dos sentidos, y se los usa ambos para argumentos que no son demostrados, como para aquellos que no necesitan demostración debido a que son en sí mismos inmediatamente obvio que son válidos. Y hemos indicado a menudo que a los argumentos con los que empieza la "primera Introducción a los Silogismos" de Crisipo se les da este título en el segundo sentido" (Sexto, Contra los lógicos, L.VIII, 223).

En esta cita se observa que el indemostrable no se refiere tanto a aquel argumento que por una razón u otra no ha estado sometido a una demostración, lo que es una cuestión fáctica, sino que tiene que ver con aquel argumento respecto del cual, por su estructura, se podría decir, no cabe hacer una demostración. Y la razón de esto último no sería sino que el argumento se demuestra por sí mismo. El término indemostrable,

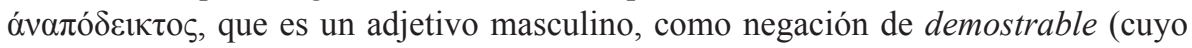
origen es el verbo mostrar, $\delta \varepsilon i ́ \kappa v v \mu$ ) indica una propiedad del argumento que hace 
que, por su propia evidencia, por una autoevidencia, aparece como ya demostrado ${ }^{26}$. De acuerdo con lo anterior, en el pensamiento estoico estaría implícito que la justificación de la deducción, de la validez, tiene una cierta ambigüedad, pues es posible verla de dos maneras: por una parte parece manifiesto que la validez sería una propiedad del argumento mismo; es él el que es autoevidente, es él el que se demuestra a sí mismo o no necesita demostración. Pero, desde otro punto de vista, parecería que la validez no podría ser radicada en la forma misma del argumento, no sería una propiedad del lenguaje sino que radicaría en un cierto acto cognitivo de aprehensión de lo correcto del movimiento inferencial y ello ya no es propiedad de un objeto formal o lingüístico sino que es una propiedad subjetiva. La validez, se podría decir, se produce como resultado de una capacidad o facultad del sujeto de aprehender la validez. Así como Aristóteles hacía descansar en la facultad del voús la capacidad de captar la verdad de un universal, los estoicos y los tratadistas antiguos vieron análogamente una cierta capacidad humana de comprender la validez argumental, aun cuando no hay expresiones que se refieran a una determinada facultad cognitiva especial para ello. En una mirada literal de las fuentes parece que los estoicos entendieron esto en términos de propiedades del argumento indemostrable mismo. Sin embargo, expresiones del tipo advertir de inmediato, mostrarse de inmediato a la comprensión, ser autoevidente, son vehículos de una posible interpretación cognitivista del asunto.

Diógenes Laercio (2005, L.VII. 79 y ss.) hace mención a que los indemostrables lo son porque no necesitan demostración. Ello implica que su validez se advierte de inmediato, o que dichos argumentos la mostrarían de inmediato a la comprensión. Por otra parte, se encuentra también en Galeno una idea equivalente al referirse a los 5 indemostrables: "Aplican el término silogismo indemostrado a unos silogismos que llevan a cabo la demostración por su propia acción o que no necesitan ninguna información externa" (Mates 1985 p. 201). Galeno parece apuntar a que la indemostrabilidad de los 5 argumentos básicos de Crísipo está en que se autodemuestran, esto es que lo hacen sin acudir a nada más que a sí mismos. La cita de Galeno parece conducir a esta pregunta: ¿Se puede interpretar la afirmación de que los indemostrables lo son porque no necesitan demostración como equivalente a que son autoevidentemente demostrables, que se demuestran por sí mismos? Parece algo contradictorio ser indemostrable y demostrarse a sí mismo.

La traducción al castellano de Mates (1985), pone "indemostrado", lo cual hace pensar más bien en un argumento que, por razones fácticas, aún no ha sido demostrado pero que podría serlo, lo cual no parece apuntar a la idea central del concepto estoico que más

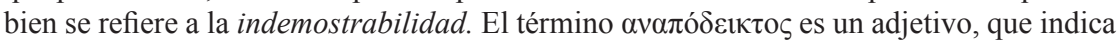
una propiedad. El problema es que, como para los estoicos $\alpha v \alpha \pi$ ó $\delta \varepsilon 1 \kappa \tau o \varsigma$ es usado tanto para los 5 argumentos simples como para cualquiera que esté compuesto de ellos, en este último caso sí cabría traducir el término por "indemostrado". Se ha preferido aquí siempre "indemostrable", porque, al menos para este artículo, el asunto de la justificación apunta siempre a los 5 básicos y no a cualquier compuesto de ellos. 
La cuestión, como se ha venido planteando en este artículo, consiste en síntesis en tratar de explorar qué se entendería por "entender de inmediato", en el giro de Diógenes que el indemostrable se entiende de inmediato. Se propone que es el enfoque cognitivista de la lógica el que podría hacerse cargo de encontrar respuestas plausibles a ello. P. Thagard afirma que la ciencia cognitiva, acerca de la cuestión de la argumentación, se pregunta: “¿Por qué las personas hacen las inferencias que hacen?” (Thagard 1996-2014, p. 4). Una respuesta desde fuera, no cognitiva, sería, porque usa las leyes de la lógica; o porque ha aprendido, junto con el lenguaje, a usar ciertos patrones inferenciales. Pero, según Thagard, cognitivamente los "patrones explicativos" son, por ejemplo, que el sujeto posee "representaciones" mentales que son equivalentes a los enunciados a nivel del lenguaje pero distintos en su naturaleza de estos. Los sujetos poseen facultades que contienen procedimientos lógicos (deductivos y no deductivos) que operan esas representaciones. Ello produce las inferencias. Pero hay otras teorías como la que afirma que no razonamos por medio de reglas de la lógica sino por medio de otros formatos, como son los modelos mentales, que no son representaciones lingüísticas. En tal sentido, la validez de los indemostrables bien puede ser pensada no solo como propiedad de objetos argumentales sino como facultades de sujetos que captan esa validez. Interpretar la justificación cognitivamente no parece tan descaminado. Por ejemplo, S. Bobzien (2002), justamente refiriéndose a Crísipo, hace recaer la visión que el filósofo tenía sobre el problema del sorites y la vaguedad en lo que la autora denomina "impresión cognitiva”. Esto está relacionado con la teoría del conocimiento de los estoicos; el conocimiento se lleva a cabo por medio de impresiones en el sujeto. Una impresión cognitiva es aquella que se produce por lo que es y así es impreso exactamente como es. El acento está puesto en cómo el sujeto capta los matices que produce un argumento sorites, y lo mismo ocurriría con los indemostrables.

Cabe señalar el reciente trabajo de M. López-Astorga (2016, 2017), quien correlaciona los indemostrables con la tesis de los modelos mentales en psicología cognitiva. La pregunta que hace el autor es por qué Crísipo consideró que esos argumentos eran indemostrables cuando de hecho solamente el primero de ellos lo es ${ }^{27}$. Una respuesta es, según López-Astorga, que Crísipo habría advertido que eran válidos por sí mismos, autoevidentes, u otro concepto análogo. Ahora bien, tal consideración puede quedar expresada y justificada acudiendo a la tesis de los modelos mentales, de Ph. JohnsonLaird (1988, 1995), como lo hace López-Astorga. Los estoicos habrían advertido un aspecto lógico, cual es que los indemostrables representaban el razonamiento humano natural. Según Johnson-Laird, el "razonamiento natural" de los sujetos se refiere al significado de los enunciados y no las estructuras sintácticas o formales de ellos (Johnson-Laird 1988, pp. 226 y ss.). El sujeto es capaz de hacer representaciones de $\neg$ p. Entonces: (i) $p \rightarrow q$ premisa; (ii) $\neg q$ premisa; (iii) p regla de introducción de hipótesis; (iv) q MP, primer indemostrable (i),(iii); (v) q $\wedge \neg$ q suma (ii) y (iv); (vi) $\neg$ p (iii) y (v) reducción al absurdo o prueba indirecta. El primer indemostrable es una regla primitiva; en cambio el segundo es derivado (i)-(vi), demostrado. 
lo que afirman los enunciados y construir modelos mentales sobre esas situaciones y, sobre esos mismos modelos obtener conclusiones atingentes a la situación modelada. Si al sujeto se le informa, por ejemplo, que A está a la izquierda de B y que éste está arriba de $\mathrm{Z}$, el sujeto puede responder sobre la localización de $\mathrm{Z}$ en relación con $\mathrm{A}$ modelando la situación, sin acudir a representaciones proposicionales necesariamente:

\begin{tabular}{|l|l|}
\hline$A$ & $B$ \\
\hline & $Z$ \\
\hline
\end{tabular}

Este modelo contiene, pues, tanto las premisas como la conclusión, esto es, se modela el argumento como tal. El modelo mental es un conjunto de tokens producto de una selección de la situación: no todas las características de una situación son modelables, pues eso depende de para qué se necesita el modelo. En el ejemplo, el color de A, B y Z no son relevantes. Además, hay más de un modelo mental para cada situación. El modelo, en muchas casos, pues, puede reemplazar al conjunto de enunciados.

El ejemplo anterior correspondía a situaciones visuespaciales, pero Johnson-Laird, en relación con lo que atañe aquí, señala modelos mentales atingentes a las constantes lógicas, como lo resalta López-Astorga. Así, el primer indemostrable requiere modelar sobre la base del condicional $\mathrm{p} \rightarrow \mathrm{q}$. Los únicos tres escenarios modelables posibles del condicional, en que éste es verdadero, son:

\begin{tabular}{|l|l|}
\hline$p$ & $q$ \\
\hline no $p$ & $q$ \\
\hline no $p$ & no $q$ \\
\hline
\end{tabular}

Según López-Astorga, entonces: "El único escenario en el cual la segunda premisa p es verdadera es el primero, en el cual q también lo es. Así, el modus ponens parece ser absolutamente natural en la mente humana" (López-Astorga 2017, p. 317). Esa naturalidad es la que Crísipo habría visto en sus 5 argumentos fundamentales. Y su justificación sería, pues, no logocéntrica.

Pero, aceptando lo anterior, ¿cómo explicar esa naturalidad?¿Y hasta dónde seguir preguntando por la justificación? Tal vez una respuesta plausible pueda provenir de la propuesta que desarrolla R. Hanna (2006), quien postula una facultad de logizar como rasgo cognitivo fundamental, un "cognitivismo lógico" (2006, p. XI), tanto o más fundamental que el recordar, percibir o conceptualizar: la lógica es construida cognitivamente por los animales racionales; los animales racionales poseen esencialmente una facultad para representar lógicamente sus acciones y el mundo (Hanna 2006, p. XI). Pero, por tanto, se trata de una facultad "protológica", que no corresponde a ningún 
sistema en particular; se distingue así de las teorías de la lógica mental, iniciadas por Piaget. La protológica es una capacidad cognitiva específica a un dominio, "rápida" (como un reflejo, con poco gasto cognitivo), pero que, a diferencia de otras capacidades cognitivas, no es encapsulada, esto es, es transversal, que conecta capacidades cognitivas entre sí. La validez de los indemostrables, en una hipótesis sustentada en lo anterior, encontraría su justificación no logocéntrica en facultades cognitivas de tipo protológico; de allí su naturalidad.

\section{Conclusión}

Dado el tipo de fuentes de la lógica estoica, acerca de la justificación solamente caben las conjeturas. La posibilidad de la justificación de la deducción se revela en el pensamiento estoico como algo bastante complejo y no explícito, que no admite una sola perspectiva pero que permite algunas interpretaciones.

Si la postura logocéntrica tiene alguna base como expediente justificador de la deducción, entonces es muy probable que los estoicos consideraran que la validez de los indemostrables fuesen ellos mismos justificadores de la deducción. Pero, desde un punto de vista no-logocéntrico, la justificación ahora de los propios indemostrables parecería descansar en la autoevidencia, en algo más allá de la propia lógica, en lo que se capta por sí mismo, sin mediar demostración alguna.Y lo que se capta por sí mismo correspondería, hoy, a aquello que una cierta facultad cognitiva del sujeto respecto de la validez lógica puede hacer.

\section{Referencias bibliográficas}

Aristóteles (2004), Posterior Analytics. Topica. Loec Classical Library, Harvard University Press, Cambridge.

Asmus C y Restall G. (2012), “A History of Consequence Relations”, en Gabbay et al. Edits.

Belnap N. (2000), “Tonk, Plonk et Plink”, en Bonnay y Cozic edits. Pp. 144-150.

Bobzien S. (2002), "Chrysippus and the Epistemic Theory of Vagueness", Proceedings of the Aristotelian Society, Vol. 102, 2012, pp. 217-238.

Bochenski J. (1961), History of Formal Logic. University of Notre Dame Press, Notre Dame.

(1947), La logique de Théofhraste. Librairie de L'Université de Fribourg en Suisse, Fribourg.

Boeri M. y R. Salles (2014), Los filósofos estoicos. Santiago: Ediciones Universidad Alberto Hurtado.

Boeri M. (2004), Los estoicos antiguos. Santiago: Editorial Universitaria. 
Boghossian P. (2000), "Knowledge of Logic", en Boghossian y Peacocke Edits., New Essays on the A Priori. Londres: Cambridge University Press.

Bonevac D. y J. Dever (2012), “A History of Conectives”, en Gabbay et al. Edits, pp. 175-233.

Bonnay D. y M. Cozic (2000), Philosophie de la logique. Paris: Vrin.

Bradley D. (2015), Critical Introduction to Formal Epistemology. Bloombsbury, Londres, N-York.

Bréhier E. (1910 / 2005), Chrisippe et l'ancien soicisme. Gordon and Breach, Londres, N.York, Paris.

Brunschwig J. (2006), Les stoiciens et leur logique. Paris: Vrin.

Burleigh W. (2009), Sobre la pureza del arte de la lógica. Bogotá: Universidad de Los Andes.

Corcoran J. (1974), "Remarks on Stoic Logic", en Corcoran edit, Ancient Logic and its Modern Interpretations. Reidel Publishing, Dordrecht / Boston.

Crísipo (2006), Testimonios y fragmentos, tomo II. Madrid: Gredos.

Diógenes Laercio (2005), Lives of Eminent Philosophes, L.VI-X, Vol II. Loeb Classical Library, Harvard University Press.

Dummett M. (1993), The Logical Basis of Metaphysics, Cap 8, "The Justification of Deduction”, pp. 184-199. Cambridge: Harvard University Press.

Falguera J. y C. Martínez (1999), Lógica clásica de primer orden. Madrid: Ed. Trotta. Fisher J. (2008), On the Philosophy of Logic. Belmont: Thomson.

Gabbay D. et al. Edits. (2012), Handbook of History of Logic, Vol 11, "Logic: A History of its Central Concepts. North Holland, Elsevier.

Gambra y Oriol (2008), Lógica aristotélica. Madrid: Editorial Dykinson.

García-Carpintero M. (1993), "The Grounds for the Model-Theoretic Account Logical Properties", Notre Dame Journal for Formal Logic, Vol. 34, º1, pp. 107-131.

Gould J. (1970), The Philosophy of Chrysippus. State University of New York Press, Albany.

(1974), "Deduction in Soic logic", en Corcoran edit., Ancient Logic and its Modern Interpretations. Reidel Publishing, Dordrecht / Boston.

Gourinat J. (2000), La dialectique des soiciens. París: Vrin.

Gourinat J. y J. Lemaire (2016), Logique et dialectique dans l'antiquité. Paris: Vrin.

Haack S. (1996), “The Justification of Deduction”, en Haack, Deviant Logic, Fuzzy logic. Chicago: University of Chicago Press, pp.183-191. 213.

(1996a), "Dummett's Justification of Deduction", en Haack 1996, pp.192-

Hanna R. (2006), Rationality and Logic. MIT, Cambridge.

Hintikka J. y M. Sandu (2007), ¿QQué es la lógica?”, en Frapolli Coord., Filosofía de la lógica. Madrid: Tecnos, pp.15-54. 
Johnson-Laird Ph. (1988), "Deduction", cap 12 de The Computer and the Mind. Massashusets: Harvard Unbiversity Press, pp .215-233. (1995), Mental Models. Cambridge: Harvard University Press.

Kneale W. y M. Kneale (2008) (1962), The Development of logic. Oxford / Nueva York: Clarendon Press.

Lemmon E. J. (2002), Beginning Logic. Indianapolis/Cambridge: Hackett Publishing Company.

Long A. y D. Sedley (1987), The Hellenistic Philosphers, Vol I. Cambridge / Nueva York: Cambridge University Press. 2012.

López-Astorga M. (2016), "The First Rule of Stoic Logic and its Relastionship with the Indemonstrables", Tópicos Revista de Filosofía 50, pp. 9-23.

(2017), "Chrysippus' Indemonstrables and the Semantic Mental Models", Eidos, $\mathrm{N}^{\circ} 26$, pp. 302-325.

Lukasiewicz J. (1934 / 1986), “Contribución a la historia de la lógica de proposiciones”, en Luis Vega, 1986, pp. 109-133.

Manzano M. y A. Huertas (2004), Lógica para principiantes. Madrid: Alianza.

Martínez C. (2007), "El status epistemológico de la lógica: verdad y necesidad", en Frápolli M. 2007, Coord., Filosofía de la lógica. Madrid: Tecnos, pp. 83-116.

Mates B. (1985), Lógica de los estoicos. Madrid: Tecnos.

Prior A. (2000), "Carte blanche por les inférences", en Bonnay y Cozic edits. Pp. 141-143.

Schechter J. y D. Enoch (2006), "Meaning and Justification: the Case of Modus Ponens", en Nous 40: 4, pp. 687-715.

Sexto Empírico (1933) 2000, Outlines of Pyrrhonism. Cambridge /Londres: Loeb Classical Library, Harvard University Press.

(1935) 1997, Against the Logicians. Cambridge/Londres: Loeb Classical Library, Harvard University Press.

Thagard P. (2014) (1996), “Cognitive Science”, Stanford Encyclopedia of Philosophy, http://plato.stanford.edu

Vega L. (1986), Lecturas de Lógica. Madrid: Universidad Nacional de Educación a Distancia, Cuadernos de la Uned No 013. 